\title{
Transcutaneous Anaesthetic Nano-enabled Hydrogels for Eyelid Surgery
}

Aikaterini Lalatsa ${ }^{a^{*}}$, Priyanka V. Patel ${ }^{\mathrm{a}}$, Yujiao Sun ${ }^{\mathrm{a}}$, Chong C. Kiun ${ }^{\mathrm{a}}$, Ferishtah

Karimi $^{\mathrm{a}}$, Jurgita Zekonyte ${ }^{\mathrm{b}}$, Krisztina Emeriewen ${ }^{\mathrm{c}}$, George M. Saleh ${ }^{\mathrm{c}}$.

anstitute of Biomedical and Biomolecular Sciences, School of Pharmacy and Biomedical Sciences, University of Portsmouth, White Swan Road, Portsmouth, PO1 2DT, UK.

bSchool of Mechanical and Design Engineering, Faculty of Technology, University of Portsmouth, Anglesea Building, Anglesea Road, Portsmouth, PO1 3DJ, UK

${ }^{\mathrm{C}}$ The National Institute for Health Research Biomedical Research Centre at Moorfields

Eye Hospital and the UCL Institute of Ophthalmology, London, EC1V 2PD, UK.

\section{*Author for correspondence}

Dr. Aikaterini Lalatsa, Reader in Nanomedicines, School of Pharmacy and Biomedical Sciences, University of Portsmouth, White Swan Road, Portsmouth, PO1 2DT, UK, Email: katerina.lalatsa@port.ac.uk, Tel: +44 239284 3929, Fax: +44 2392843565. 


\section{Graphical Abstract}

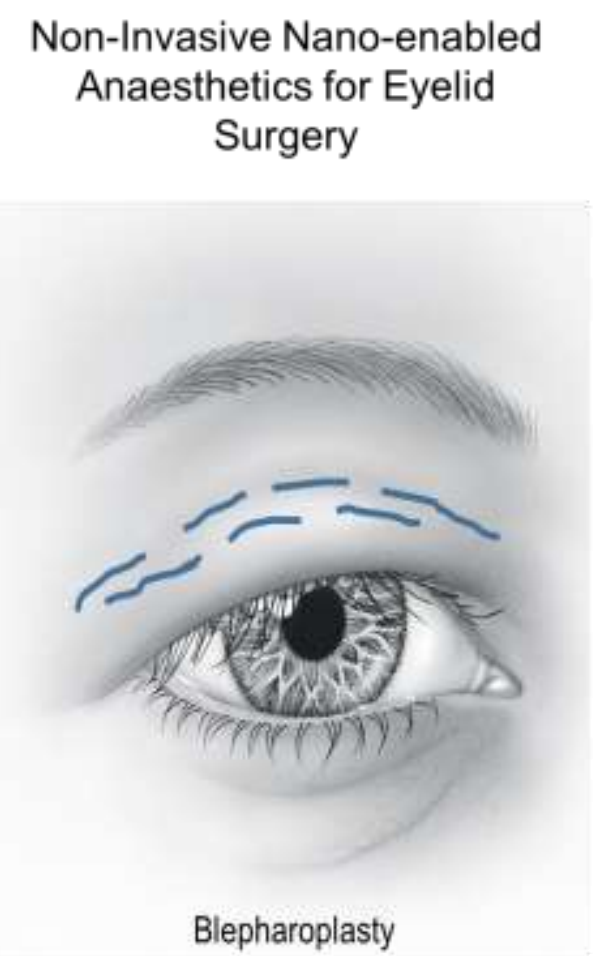

50
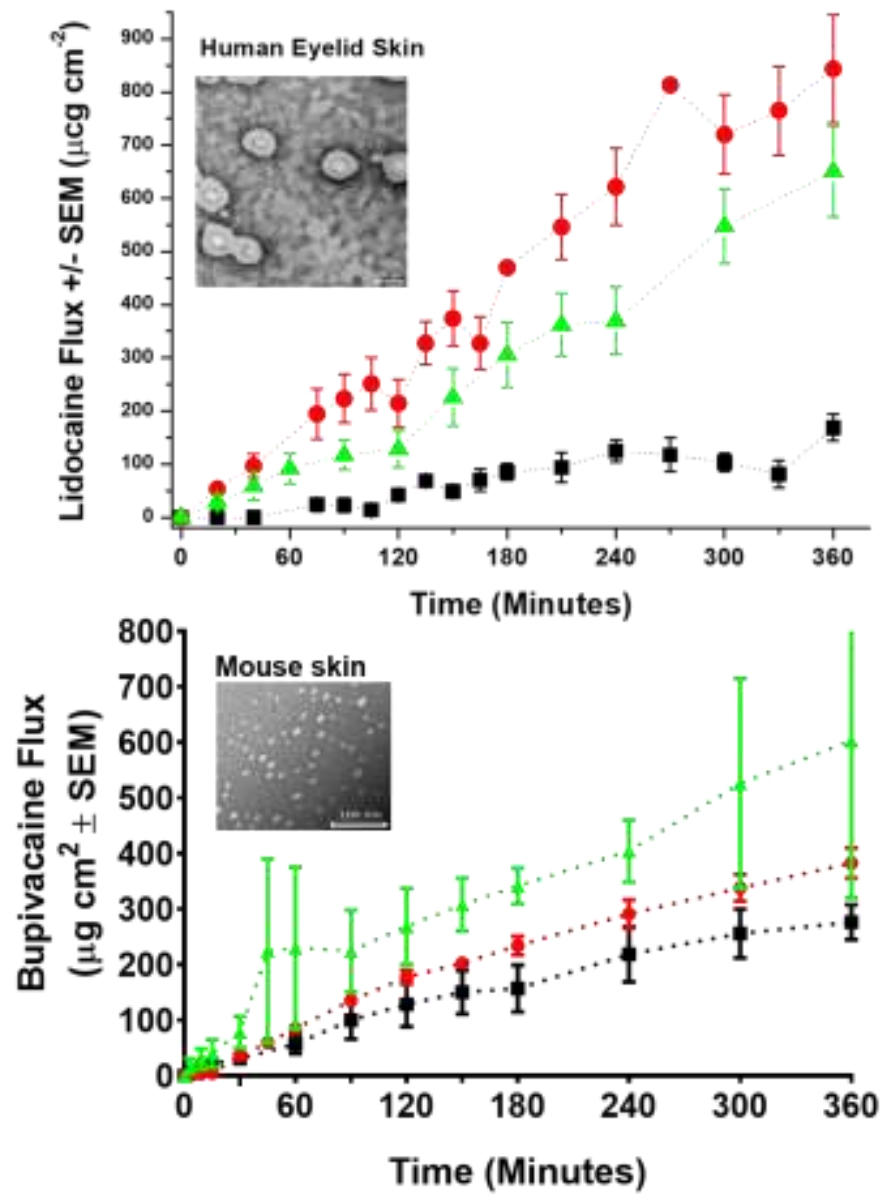
60

\section{Abstract}

Local anaesthetics are administered as a diffuse superficial slow injection in blepharoplasty. Current transcutaneous local anaesthetic formulations are not licensed for use on the face due to safety concerns. Here we report for the first time the permeation of local anaesthetics (lidocaine, bupivacaine loaded SNEDDS and

65 their hydrogels) across human eyelid and mouse skin as a novel and ocular safe formulation for eyelid surgery. SNEDDS were loaded with high levels of anaesthetics and incorporated within carbomer hydrogels to yield nano-enabled gels. Lidocaine hydrogels have a significantly reduced lag time compared to EMLA, while they enhance lidocaine flux across human eyelid skin by 5.2 fold. Ex vivo tape stripping experiments indicated localisation of anaesthetics within the stratum corneum and dermis. Initial histopathological studies have shown no apparent signs of skin irritation. These results highlight the potential clinical capability of nano-enabled anaesthetic hydrogels as a non-invasive anaesthetic procedure for eyelid surgery.

\section{Key Words}

Lidocaine, Bupivacaine, Anaesthetics, Self-nanoemulsifying drug delivery systems

90 (SNEDDS), hydrogels, eyelid, tape stripping, franz cell diffusion assays. 


\section{Introduction}

Blepharoplasty, a surgical procedure for removal of excess skin and adipose tissue from the upper or lower eyelids, can be functional to correct for "droopy" upper eyelids

95 but also cosmetic and is the second most popular surgical procedure in men and women [1]. Local anaesthesia and intravenous sedation are frequently used for patients undergoing upper eyelid surgery, even though general anaesthesia might be desirable for some patients e.g. patients with needle phobias [2]. Local anaesthesia is usually administered as a diffuse superficial slowly subcutaneous injection along the

100 lid skin crease [3]. Local anaesthesia in eyelid and intraocular surgery carries inherent risks such as haemorrhage, swelling, tissue distortion and obscuration of surgical landmarks, collateral damage [2]. Thus, there is a clear need for ideally needless alternatives for anaesthetic delivery to match this increasingly unmet clinical need.

Transcutaneous delivery of anaesthetics have been used as successful alternatives

105 to invasive anaesthetic procedures to minimise anxiety, pain and discomfort during dermatological surgical procedures [4]. The clinical efficacy of topically administered anaesthetics depends on the pharmacological and physicochemical properties of the molecule and its ability to transverse the superficial layers of the skin [5]. Most local anaesthetics (LAs), as relatively hydrophobic ionisable amines, undergo partitioning

110 into lipids in order to reversibly inhibit the generation and propagation of the action potential by blocking the neuronal voltage-gated sodium channel while changing the lipid membrane fluidity at the surrounding area [4]. Their physicochemical properties (pKa and hydrophobicity) and their varied efficacy depending on the thickness and hydration of the stratum corneum (SC), necessitates that LAs are administered in 115 some cases using a needle to provide effective dermal anaesthesia. 
EMLA cream is commonly used for local anaesthesia prior dermatological procedures. EMLA is an $1: 1$ oil/water emulsion with the oily phase comprised by an eutectic mixture of lidocaine $2.5 \% \mathrm{w} / \mathrm{w}$ and prilocaine $2.5 \% \mathrm{w} / \mathrm{w}$ cream, while the aqueous phase consists of synthetic high molecular weight polymers of acrylic acid that are cross-

120 linked with either allyl sucrose or allyl ethers of pentaerythritol that are gelled with sodium hydroxide by screening the carboxylic acid charges which results in the cream's alkaline $\mathrm{pH}$. This alkaline $\mathrm{pH}$ of EMLA contra-indicates its use for administration to eyelid skin. The eutectic mixture of the anaesthetics lowers their melting point, hence solubilising the crystalline anaesthetics for incorporation within

125 the topical preparation in high concentrations [5-7]. However, administration of EMLA cream on intact skin is needed for at least one hour prior achieving a depth of anaesthesia of $3 \mathrm{~mm}$, while a two hour application is needed to reach a depth of $5 \mathrm{~mm}$ [8]. Other topical anaesthetic gels such as AMETOP gel (tetracaine $4 \% \mathrm{w} / \mathrm{w}$ xantham gum gel) still requires 30-45 minutes application prior operation with the anaesthesia

130 lasting for 4-6 hours, but there have been reports of eyelid oedema, itching and blistering associated with its use [7].

Eyelid skin offers advantages for topical delivery due to the reduced thickness compared to other parts of the body $(0.05 \mathrm{~cm}$ compared to that of the palm and sold of $0.4 \mathrm{~cm}$ ) [9]. The eyelid skin surface is highly hydrated similarly to adjacent facial

135 skin, but possesses extremely low amounts of surface lipids, unlike neighbouring skin regions [9]. Corneocytes of the eyelid skin display a significantly large surface size, while the SC turnover remains slow allowing for sufficient maturation of corneocytes that enables them to exert efficient water binding capacity [9]. Eyelid $\mathrm{pH}$ tends to be higher $(\mathrm{pH} 6.0 \pm 0.05)$ than that of facial skin [9]. Thus, an ideal non-invasive 140 anaesthetic formulation for eyelid surgery should aim to promote the permeation of 
anaesthetics via the thin, hydrated eyelid skin with a rapid onset of action, adequate duration of action and low toxicity.

Lipidic nanoparticles (e.g. solid lipid nanoparticles), polymeric micelles and microemulsions such as self-nanoemulsifying drug delivery systems (SNEDDs) have

145 shown promise in the topical delivery of LAs [10]. In our previous work, we compared permeation of these three types of promising nanomedicines prepared using safe (GRAS) excipients with high loading of lidocaine for the topical delivery of anaesthetics. Lidocaine SNEDDS illustrated high drug loading, high colloidal stability compared to other nanomedicines with a short lag time achieving high concentrations

150 within the first hour [5]. Here we report for the first time the permeation of LAs loaded SNEDDS and their respective hydrogels across human eyelid and mouse excised skin tissue as a novel and ocular safe formulation for eyelid surgery.

\section{Material and methods}

\subsection{Materials}

Lidocaine (99+\%) and all other chemicals and solvents were purchased from Sigma Aldrich (Dorset, UK). Bupivacaine (98+\%) was purchased from Alfa Aesar (Heysham, UK). Labrasol (Caprylocaproyl macrogol-8 glycerides), Transcutol P (diethylene glycol monoethyl ether) and Capryol 90 (Propylene glycol monocaprylate) were obtained from Gatefosse (Alpha Chemicals, Berkshire, UK). Carbopol 940 was purchased from Fisher Scientific UK (Loughborough, UK). The artificial skin (cellulose acetate membranes, Visking dialysis tubing, cut-off: $12-14 \mathrm{KDa}$, thickness: $2 \mathrm{~mm}$ ) were purchased from Medicell Membranes Ltd (London, UK). Franz cells were specially made by Soham Scientific Ltd (Fordham, UK). 


\subsection{Excised human skin samples}

Excised human eyelid samples were collected (Dr GM Saleh and Dr K EmeriewenMoorfields Eye Hospital) from patients undergoing eyelid surgery for clinical or cosmetic reasons after full institutional review board and ethical committee approval

170 was obtained (NHS Health Research Authority North Wales REC (Central and East) 13/WA/0066 for IRAS project ID 117286: " Nanoparticle behaviour in human and artificial skin tissue"). The human skin $(0.4-0.7 \mathrm{~mm})$ was frozen on the day of excision and stored in water-impermeable plastic bags at $-80^{\circ} \mathrm{C}$ (SANYO, Buckinghamshire, UK) until required. Skins samples were used within 10 months of excision (specimens

175 are certified to be viable for a period of 5 years [11]). Skin samples were thawed in acetate buffer $\left(20 \mathrm{mM}, \mathrm{pH} 6.00 \pm 0.1,37^{\circ} \mathrm{C}\right)$ and hair, muscle or fat tissue, if any, were removed prior to sample mounting on Franz cells.

\subsection{Excised mouse skin samples}

NMRI male mice (8 weeks old, 25-28g) purchased from Harlan Iberica (Barcelona,

180 Spain) were euthanised and the skin was removed and frozen on the day of excision and stored in water-impermeable plastic bags at $-80^{\circ} \mathrm{C}$ until required. Skin samples were used within 2 months of excision. Skin was thawed and shaved using a scapel and the skin was placed in $60^{\circ} \mathrm{C}$ de-ionised water for 30 seconds prior to removal of the epidermis from the dermis and hypodermis. The epidermis was then placed in 185 acetate buffer $\left(20 \mathrm{mM}, \mathrm{pH} 6.00 \pm 0.1,37^{\circ} \mathrm{C}\right)$ prior being mounted on the Franz cells for diffusion assays.

\subsection{Preparation of Lidocaine and Bupivacaine SNEDDS}

Lidocaine SNEDDS (10 or $20 \% \mathrm{w} / \mathrm{w}$ ) (LID-SNEDDS) and Bupivacaine SNEDDS (2 or $5 \% \mathrm{w} / \mathrm{w}$ ) (BUP-SNEDDS) were prepared by dispersing lidocaine (1 or $2 \mathrm{~g}$ ) or 190 Bupivacaine $(0.2$ or $0.5 \mathrm{~g})$ within an isotropic mixture of Labrasol (3g), Capryol 90 (1g) 
and Transcutol P (6g) respectively [5]. The ratio of oil:surfactant and solvent was optimised in terms of particle size using tertiary diagrams and choice of surfactants and solvents was based on solubility studies [5, 12]. The LID-SNEDDS and BUPSNEDDS were magnetically stirred for 15 minutes and left in an agitated water bath

195 (50 rpm, Kotterman D1365, Hanigsen, Germany) at $37^{\circ} \mathrm{C}$ overnight for 16 hours [13]. Mixtures of the two drugs can be prepared by adding both of the drugs together in the required concentrations or by mixing finally prepared SNEDDS in required ratio.

\subsection{Preparation of LID-SNEDDS Gels $(10 \% \mathrm{w} / \mathrm{w})$ and BUP-SNEDDS Gels $(2 \% \mathrm{w} / \mathrm{w})$}

Carbopol $940(1 \mathrm{~g})$ was added in de-ionised water $(25 \mathrm{~mL})$ and left to swell overnight.

200 LID SNEDDS (20\% w/w, 10g) were added dropwise to the Carbopol gel ( $4 \% \mathrm{w} / \mathrm{w}, 10 \mathrm{~g})$ and mixed in a mortar and pestle. The $\mathrm{pH}$ was adjusted to $\mathrm{pH} 6.0 \pm 0.1$ (Accumet AB200 pH meter, Fisher Scientific, Loughborough, UK) using neat glacial acetic acid $(\sim 200-250 \mu \mathrm{L})$ to prepare the final LID-SNEDDS gels $(10 \% \mathrm{w} / \mathrm{w})$. Sodium hydroxide $(1 \mathrm{M}, 0.14 \mathrm{~g})$ was added to swollen Carbopol gel $(4 \% \mathrm{w} / \mathrm{w}, 4 \mathrm{~g})$ and mixed prior the

205 addition of BPQ-SNEDDS ( $5 \% \mathrm{w} / \mathrm{w}, 2.86 \mathrm{~g})$ to yield final BUP-SNEDDS gels $(2 \% \mathrm{w} / \mathrm{w})$ with a final $\mathrm{pH}$ of $6.0 \pm 0.1$.

\subsection{Measurement of particle size and zeta potential of prepared SNEDDS and} SNEDDS loaded gels.

All formulations were diluted ( 1 in $1000 \mathrm{v} / \mathrm{v}$ ) with de-ionised water $(\mathrm{pH} 6.5 \pm 0.1)$.

210 SNEDDS samples were vortexed and left to stand for 15 minutes prior analysis. Gels were diluted and centrifuged (5,000 rpm, 5 minutes, SciSpin Micro Centrifuge, Shropshire, UK) to remove carbomer, which is insoluble in water, and the supernatant was left to stand for 15 minutes prior to analysis. Particle size and zeta-potential was measured as previously described using a Nano-ZS Zetasizer (Malvern Instruments,

215 Worcestershire, UK) $[5,14,15]$. 


\subsection{Morphology of SNEDDS and SNEDDS enabled gels (TEM, AFM).}

A drop of the aqueous diluted formulations for particle size measurements was placed on a Formvar/Carbon coated grid (F196/100 3.05 mm, mesh 300, TAAB Labs Ltd, Berks, UK) prior staining with $2 \%$ uranyl acetate and transmission electron microscopy

220 (TEM) imaging as previously described $[5,14,15]$.

Similarly, the aqueous diluted formulations $(5 \mu \mathrm{L})$ were placed on the surface of muscovite mica $\left(1 \mathrm{~cm}^{2}\right.$, Agar Scientific, Essex, UK) and left to dry for 2 minutes, and dried under nitrogen gas prior to being attached to a nickel disk $\left(1 \mathrm{~cm}^{2}\right)$ using doubleside adhesive tape and placed on the AFM scanner (Multi-Mode/Nanoscope IV

225 scanning proble microscope, Bruker, Santa Barbara, CA, USA). Measurements were performed in air under ambient conditions $\left(T=23^{\circ} \mathrm{C}, \mathrm{RH}=21 \%\right)$ using the $\mathrm{J}$-scanner $(\max x y=200 \mu m)$. Scanning was performed in tapping mode using Si cantilevers with integrated tips $\left(\mathrm{t}=3.6-5.6 \mu \mathrm{m}, \mathrm{I}=140-180 \mu \mathrm{m}, \mathrm{w}=48-52 \mu \mathrm{m}, \mathrm{V}_{\mathrm{o}}=288-338 \mathrm{kHz}, \mathrm{k}\right.$ $=12-103 \mathrm{~N} \mathrm{~m}^{-1}, \mathrm{R}<7 \mathrm{~nm}$; OTESPA, Bruker, France) and an RMS amplitude of $0.8 \mathrm{~V}$.

230 The images were processed and dimensions measured using Nanoscope Analysis software (V1.4, Bruker).

\subsection{Rheology studies of EMLA and LID-SNEDDS gel}

The viscosity of LID-SNEDDS gel $(10 \% \mathrm{w} / \mathrm{w})$ or EMLA was measured by placing $\sim 2 \mathrm{~g}$ of the formulation on the Peltier temperature controlled platform of an AR 2000

235 rheometer (TA Instruments, Elstree, UK) and using a Carri-Med cone $4 \mathrm{~cm}$ flat plate. Continuous ramp conditions were used at $37^{\circ} \mathrm{C}$ with a 2 -minute equilibration time. The shear rate was set at 0.1-100 1/s with a total duration time of 20 minutes. A log mode was used and measurements were taken at 10 points per decade.

\subsection{In vitro Franz cells diffusion studies}


240 Modified Franz diffusion cells displayed an approximate diffusional area of $0.07 \mathrm{~cm}^{2}$ [5]. After the compartments were rinsed with an acetate buffer $(20 \mathrm{mM}, \mathrm{pH} 6.0 \pm 0.1)$ and a $3 \times 2 \mathrm{~mm}$ stirrer bar was added to the receiver compartment, the compartment was filled up with $2 \mathrm{~mL}$ of acetate buffer [5]. The washed cellulose acetate membranes were cut into square pieces $\left(0.2 \mathrm{~cm}^{2}\right)$ or human eyelid skin with the $\mathrm{SC}$ facing upwards 245 were mounted to adequately cover the receptor chambers. The donor compartment and the receptor compartment were tightly sealed using Parafilm ${ }^{\mathrm{TM}}$ and clamped together. The donor chamber was filled with acetate buffer $(1 \mathrm{~mL})$ and placed in a waterbath at $37^{\circ} \mathrm{C}$ (RCT basic, IKA ${ }^{\circledR}$ England Ltd, Oxford, UK). After 1 hour, the acetate buffer was removed from the receptor chamber and collected for analysis. The receptor chamber was refilled with fresh acetate buffer pre-warmed to $37^{\circ} \mathrm{C}$. The acetate buffer in the donor chamber was removed and the formulation (EMLA; 1g, LIDSNEDDS $10 \% \mathrm{w} / \mathrm{w}$, LID-SNEDDS gel $10 \% \mathrm{w} / \mathrm{w} ; 0.8 \mathrm{~g})$ was added to the donor chamber ensuring it was in contact with the artificial or human skin. Syringes were activated five times prior to sampling $(0.2 \mathrm{~mL})$ at predetermined times from the receptor chamber using a $1 \mathrm{~mL}$ syringe with a $21 \mathrm{~g}$ needle (38 $\mathrm{mm}$ in length) and samples were analysed by HPLC as described below. The receptor chamber was immediately replenished with pre-warmed acetate buffer $(0.2 \mathrm{~mL})$.

After 9 hours of exposure, the human skin samples were wiped with an ethanol impregnated cotton bud, and the samples were fixed using formalin (10\%, neutral) for

260 a minimum of 48 hours in the fridge till processed for histopathology studies as described below.

Solubility studies were conducted for bupivacaine in six different receptor chamber media to allow for the selection of receptor media that will ensure sink conditions during diffusion studies. The tested media included acetate buffer $(20 \mathrm{mM}, \mathrm{pH} 6.0 \pm$ 
265 0.1), ethanol: acetate buffer (6:4 v/v), 2-hydroxypropyl-b-cyclodextrin (1\%, pH $6.0 \pm$ $0.1)$, Soluplus ( $1 \% \mathrm{w} / \mathrm{v}, \mathrm{pH} 6.0 \pm 0.1)$, phosphate-buffered saline $(50 \mathrm{mM}, \mathrm{pH} 7.4 \pm$ $0.1)$ and sodium chloride $(0.9 \%)$. Bupivacaine $(10 \mathrm{mg})$ was dispersed in the media (1 $\mathrm{mL})$ and allowed to stir for 24 hours at $37^{\circ} \mathrm{C}$ prior centrifugation $(5,000 \mathrm{rpm}$ for 5 minutes) and analysis of the supernatant after dilution using HPLC. Ethanol: acetate buffer demonstrated high solubility and was thus selected. Cellulose acetate and NMRI male mouse skin was used for diffusion studies of BUP-SNEDDS (5\% w/w) and BUP-SNEDDS gel $(2 \% \mathrm{w} / \mathrm{w})$ were performed using specially manufactured Franz diffusion cells (receptor chamber: $3 \mathrm{~mL}$, donor chamber: $1 \mathrm{~mL}$, diffusion area: 1.19 $\mathrm{cm}^{2}$ ) as described above. However, the receptor chamber of the Franz cells were filled

275 with ethanol: acetate buffer and a PTFE stirrer bar $(6 \times 2 \mathrm{~mm})$ were used instead. The formulations, BUP in DMSO (2\%, $1 \mathrm{~mL})$, BUP-SNEDDS (0.4g), and BUP-SNEDDS gel $(1 \mathrm{~g})$ were added to the donor chamber and samples $(0.3 \mathrm{~mL})$ were taken at predetermined time points prior to HPLC analysis.

After 24 hours of exposure, the mouse skin samples were wiped with an ethanol

280 impregnated cotton bud. Skin was cut in half and one half was homogenised with 25 $\mathrm{mL} / \mathrm{g}$ of ethanol: acetate buffer, centrifuged at 5,000 rpm for 10 minutes and the supernatant was analysed by HPLC for drug content, while the other was fixed as above for histopathology studies.

\subsection{Ex vivo tape stripping experiments}

285 Permeability of BUP in DMSO, BUP-SNEDDS and BUP-SNEDDS gels was carried out using custom made Franz diffusion cells (receptor chamber: $3 \mathrm{~mL}$, donor chamber: $1 \mathrm{~mL}$, diffusion area: $1.13 \mathrm{~cm}^{2}$ ). After the receptor compartment was rinsed with an ethanol: acetate buffer $(20 \mathrm{mM}, \mathrm{pH} 6.0 \pm 0.1)(6: 4 \mathrm{v} / \mathrm{v})$, a $6 \times 2 \mathrm{~mm}$ stirrer bar was added to the receiver compartment and filled with the same buffer. The donor 
compartment was placed over NMRI male mouse excised skin and loaded with BUP in DMSO (1mL, 2\% w/v), BUP-SNEDDS (1g, 5\% w/w) and BUP-SNEDDS gels (1g, $2 \% \mathrm{w} / \mathrm{w})$. Skin was exposed to formulations for 30 or 60 minutes $(n=3)$. Skin was then collected and cleaned three times with cotton tips and three times with tips dipped in ethanol: acetate buffer. The skin was weighted and placed on a flat surface with the

295 SC facing up. Skin stripping was carried out using tapes (13mm, round self-adhesive stickers, Party Decor ${ }^{\mathrm{TM}}$, UK) that were pressed for 30 seconds under slight manual pressure using a custom made weight (13 mm, 61.235g). Tape strips collected before and after tape stripping were weighted and 40 sequential tapes were collected in tubes containing $0.25 \mathrm{~mL}$ of ethanol: acetate buffer, shaken for 15 minutes (Microscopic 300 mixer, SciQuip, Shropshire, UK), bath sonicated for 15 minutes (Grant ultrasonic bath, XUB13, Cambridge, UK) and finally centrifuged (5,000 rpm, 10 minutes). The supernatant was analysed by HPLC as shown below. The remaining mouse skin was homogenised with $25 \mathrm{~mL}$ of ethanol: acetate buffer / g of skin, filtered through $0.2 \mu \mathrm{m}$ nylon filters and analysed by HPLC.

\subsection{Quantification of Lidocaine and Bupivacaine levels using HPLC}

Lidocaine was quantified as previously described [5]. A stock solution of bupivacaine (1 $\mathrm{mg} \mathrm{mL}^{-1}$ in DMSO) was diluted with ethanol: acetate buffer $(6: 4 \mathrm{v} / \mathrm{v})$ to prepare standards (1-100 $\left.\mu \mathrm{g} \mathrm{mL}^{-1}\right)$. A Phenomenex Hypersil BDS C18 column (150 x $4.6 \mathrm{~mm}$, $5 \mu \mathrm{m}$ ) was maintained at $25^{\circ} \mathrm{C}$ for analysis at $220 \mathrm{~nm}$ using an Agilent 1100 series

310 HPLC attached to a PDA detector [5]. Samples $(40 \mu \mathrm{L})$ were eluted at $1.2 \mathrm{~mL} \mathrm{~min}^{-1}$ using an acetate buffer $(50 \mathrm{mM}, \mathrm{pH} 6.0 \pm 0.1)$ : acetonitrile mobile phase $(64: 36 \mathrm{v} / \mathrm{v})$ with bupivacaine having a retention time of $7.3 \mathrm{~min}$.

\subsection{Histopathological analysis of human and mouse treated skin.}


Fixed treated human skin (9h) with lidocaine formulations and mouse skin (24h) with bupivacaine formulations were prepared and imaged and previously described [16].

\section{Results}

Prepared LAs-SNEDDS and LAs-SNEDDS gels illustrated sizes consistently below $300 \mathrm{~nm}$ (Table 1), good colloidal stability and quasispherical morphology (Figure 1).

320 The amount of LAs loaded was chosen based on the concentration of clinically approved formulations for both LAs in order to avoid toxicity of formulations, however, these can be tailored accordingly if combination products are needed (to ensure a longer and deeper anaesthesia). To ensure gels possessed appropriate viscosity for application to the skin by patients, we compared their rheological properties with

325 EMLA. Both EMLA and LID-SNEDDS gel demonstrated a shear thinning (pseudoplastic) behaviour and have demonstrated comparative viscosity to EMLA cream ( $p>0.05,2$-tailed Student T-test) (Figure 2A).

Linear permeation profiles were observed for both EMLA, LID-SNEDDS and LIDSNEDDS gels (Figure 2B,C). Across artificial skin, LID-SNEDDS gels enhanced

330 permeation by 14.7 fold (EMLA Jss: $30 \pm 4.2 \mu \mathrm{g} \mathrm{cm}^{-2} \mathrm{~h}^{-1}$, LID-SNEDDS gel Jss: 155.4 $\pm 37.2 \mathrm{\mu g} \mathrm{cm}^{-2} \mathrm{~h}^{-1}$ ) with no determinable lag time and reaching the plateau after 2.5 hours while EMLA demonstrated a lag time of $23.8 \pm 35.2$ minutes and reached plateau levels after 4 hours (Figure 2B). Across human excised eyelid skin, LIDSNEDDS gel demonstrated a significant reduced lag time compared to EMLA (9.1 \pm 19.1 vs $49.8 \pm 12.7$ minutes), while they enhanced flux at steady state by 5.2 fold and the permeability co-efficient by 1.6 fold (Table 2 ). We attempted to analyse the steady state flux in skin samples of male and female patients as we observed higher fluxes in female patient skin, however results were not significant possibly due to small size of 
available male patient samples. An increased lag time was observed in male patients,

340 which could be attributed to the slightly higher skin thickness of male patient samples compared to female $(0.098 \pm 0.01 \mathrm{~cm}$ vs $0.088 \pm 0.06)$. Comparing the correlation coefficients for various release mathematical models, the Korsmeyer-Peppas model was found to best fit lidocaine release from each formulation tested across human eyelid skin (Table 3).

345 Amongst media tested to ensure sink conditions for permeability studies, ethanol: acetate demonstrated by far the highest solubility (Figure 2A). Across artificial skin, BUP-SNEDDS and BUP-SNEDDS gels demonstrated a linear permeation profile (BUP-SNEDDS Jss: $95.52 \pm 17.31 \mu \mathrm{g} \mathrm{cm}^{-2} \mathrm{~h}^{-1}$, BUP-SNEDDS gel Jss: $41.31 \pm 6.85$ $\mu \mathrm{g} \mathrm{cm}^{-2} \mathrm{~h}^{-1}$ ) with almost no determinable lag time (BUP-SNEDDS: $3.66 \pm 4.32$ minutes,

350 BUP-SNEDDS gels: 0 minutes) (Figure 2B, Table 4). Across mouse skin with similar thickness to eyelid skin, flux for all formulations tested were not statistically significant (Repeated measures One-Way Anova, p>0.05). BUP-SNEDDS gels enhanced the permeability co-efficient by 1.4 compared to Bupivacaine in DMSO. As with lidocaine formulations, the Korsmeyer-Peppas model was able to fit better the bupivacaine release from nano-enabled formulations, while a zero-order release was observed for bupivacaine in DMSO solutions (Table 3).

Ex vivo tape stripping were undertaken to access BUP levels within the SC and dermis after 30 and 60 minutes of exposure to the formulations. The cumulative weight per unit area of $S C$ removed by sequential tape-stripping (mean $\pm S D ; n=9$ ) is linear and analysis of variance followed by Scheffe's F-test shows that the weight of the SC removed per strip is independent of the tape-strip number per formulation $(p>0.05)$. Both time points selected for tape stripping experiments based on previously calculated lag times (Table 4) were collected after steady state was established 
(texp $\left.>1.7 t_{\text {lag }}\right)$ [17]. Thus, equation 1 was used to calculate the partition co-efficient of

BUP between the SC and the vehicle $\left(\mathrm{K}_{\mathrm{sc} / \mathrm{v}) \text { : }}\right.$

$$
K s c / v=\frac{2}{L_{S C} \mathrm{AC}_{v}^{o}}+\sum_{i=1}^{N T S} m i
$$

where $L_{s c}$ is the effective thickness of the SC, $A$ the surface area of exposure i.e. being tape stripped and $\mathrm{C}_{v}^{O}$ the initial concentration of BUP in the vehicle [17]. Values are summarised in Table 5. Considering that the thickness of the SC from the back of

$370 \mathrm{NMRI}$ mice is approximately $15 \mu \mathrm{m}$ [18], the concentration in the $\mathrm{SC}(15 \mu \mathrm{m})$, dermis $(\sim 15 \mu \mathrm{m})$ and remaining homogenised skin is summarised in Table 5 and cumulative bupivacaine levels and cumulative mass of skin stripped per tape number are shown in Figure 4. At 30 minutes, levels of bupivacaine DMSO in the dermis are 5 fold lower thatn levels achieved by both the BUP-SNEDDS and BUP-SNEDDS gels ( $p>0.05)$, although levels obtained from homogenising the remaining of the skin are signficantly higher than levels of the nano-enabled formulations ( $p>0.05$, One-way ANOVA). Thus, DMSO as a penetration enhancer can result in levels that can reach the blood but without localising the formulation in the dermis (where nerve endings are present) after a short pre-operative exposure time. After one hour, there is no significant difference in levels of bupivacaine in the dermis amongst the 3 formulation (applied at the same bupivacaine dose). However, the levels of bupivacaine in the homogenised skin are $38 \%$ lower than those of bupivacaine DMSO ( $p>0.05$, One-way ANOVA), indicative of dermis localisation of the formulaiton. Tape stripping can vary depending of type of formulation used and has been particularly difficult for oily formulations [19].

385 This is something that we observed in our study as well as a higher number of tapes were needed for SNEDDS compared to DMSO and nano-enabled hydrogels to ensure we remove an effective thickness of $15 \mu \mathrm{m}$. Histopathology studies of remaining skin 
after removal of 40 tapes have also confirmed the absence of the complete removal of the SC (data not shown).

390 There are no apparent signs of skin irritation (e.g. oedema or erythema) on visual examination of the skin samples following treatment with blank SNEDDS, LIDSNEDDS, LID-SNEDDS gel or mouse skin samples following treatment with BUPSNEDDS and BUP-SNEDDS gel. Skin treated with SNEDDS or SNEDDS gels were devoid of inflammatory cells and no disruption of the epidermal and dermal layers was evident (Figure 5), with no signs of acanthosis or hyperkeratosis.

\section{Discussion}

The increasing number of blepharoplasty and associated eyelid procedures

400 undertaken annually necessitates the development of a non-invasive anaesthetic procedure that is efficacious and safe without the need for subcutaneous injection of anaesthetics. Here we present an ocular safe nano-enabled gel from GRAS excipients for the delivery of anaesthetics or anaesthetic mixtures based on nano-emulsifying drug delivery systems incorporated into a cross-linked polyacrylate polymers

405 (carbomers). Preference of patients to hydrogel formulations and preparation of anaesthetic gels with GRAS excipients minimises barriers for use of the developed nano-enabled hydrogel in a clinical setting considering the ease of scalability of our described formulation. SNEDDS were optimised by ternary phase diagrams to identify optimal ratios for type IV SNEDDS with a good solvent capacity [5].

410 Previous studies have reported a clear correlation of enhanced LA solubility with medium chain triglycerides (MCT) consisting of caprylic/capric acid triglycerides [20]. Thus, apart from Transcutol, a high Labrasol content can aid in improving the drug 
loading, LA permeability and efficacy of LA. MCT enhance LA efficacy against cold sensation (reaching cold receptors in the epidermis) possibly due to their ability to

415 interact with similar properties lipids present in the SC $[5,20]$. SNEDDS are able to load extremely high levels of anaesthetics [>749.955 $\pm 9.567 \mathrm{mg} \mathrm{g}^{-1} \mathrm{mg}$ Lidocaine and $>50$ mg Bupivacaine per $1 \mathrm{~g}$ of SNEDDS [5]] and combinations within currently used clinically doses is possible by simply mixing SNEDDS at needed proportions and then loading within hydrogels as shown above. Lidocaine is the most commonly used LA in eyelid surgery, due to its potency, rapid onset ( $<2$ minutes) and moderate duration of action (30-45 minutes) [5]. Bupivacaine, on the other hand, has a slightly slower onset of action (typically 2-10 minutes) but results to a longer duration of action and elicits effective nerve block [21, 22]. Typically, both are used with adrenaline in eyelid surgery to limit haemorrhage and elicit vasoconstriction to reduce systemic uptake and clearance of the anaesthetics [2, 23]. Adrenaline can be added to our gels just prior administration. This platform technology can yield combination anaesthetics with a quick onset of action and able to maintain depth of anaesthesia by tailoring the amount and type of anaesthetics used. This has been achieved by eutectic mixtures (e.g. EMLA), but careful titration of anaesthetic levels are needed to ensure stability of these formulations, while they are not designed or are safe for ocular use.

Particle size of our nano-enabled LA formulations was consistently below $300 \mathrm{~nm}$ with a low polydispersity $(<0.4)$ and adequate colloidal stability $(<-30 \mathrm{mMV})($ Table 1$)$. Near spherical morphology with an electrodense core was observed (Figure 1) for nanoenabled formulations with LID-SNEDDS particles demonstrating a core-shell morphology indicative of a dense packing within the core of the particle due to high drug loading. Differences in the size from TEM as compared with their hydrodynamic 
diameter from DLS data is likely attributed to sample drying for AFM and TEM sample preparation and imaging respectively [24].

Dilution of SNEDDS loaded gels in aqueous media, results in nanoparticulate 440 suspensions of similar size and morphology $(p>0.05)$. When LID-SNEDDS are incorporated in the swollen carbomer hydrogel (acidic $\mathrm{pH}$ ), a rapid increase in $\mathrm{pH}$ is observed (>8) resulting from the interaction between the amine of lidocaine and the free carboxylic groups of carbomer 940 resulting in an opaque gel. The carbomer gel behaves as a reservoir of lidocaine in which a high proportion of the drug is available 445 as the ion pair form $\left(\mathrm{R}-\mathrm{COO}-\right.$ Lidocaine $\left.\mathrm{H}^{+}\right)[25,26]$. When the $\mathrm{pH}$ is titrated using dilute hydrochloric acid to a $\mathrm{pH}$ of $6.0 \pm 0.1$, lidocaine is present in the ionised state (Lidocaine $\mathrm{H}^{+}$) and gradual entrapment of lidocaine within the particle core of SNEDDS is possible yielding a clear shiny gel. This step is only needed for lidocaine hydrochloride. When unloaded or when the free base of bupivacaine is used, this $\mathrm{pH}$ change is not observed 450 and $\mathrm{pH}$ is raised to a $\mathrm{pH}$ of 6.0 with dilute sodium hydroxide to yield the final gel [26]. The clarity of the latter gels also indicates that the high water content ( $>40 \%)$ of our loaded hydrogels is not responsible for translucency, as previously reported for lidocaine hydrogels [26]. Shear thinning observed for LID-SNEDDS gels is typical for carbomer 940 gels [27]. Variability in viscosity with our gels is explained by the particle size and polydispersity of the four batches tested as there is an inversely proportional relationship between gel viscosity and size of nanoparticulate dispersions.

Transport from the gels was best described by the Korsmeyer-Peppas model $(n<1)$ (Table 3). As release was from a slab and $\mathrm{n}$ was below 1, lidocaine or bupivacaine release was non-Fickian (anomalous). The anomalous diffusion mechanism 460 demonstrates both diffusion controlled and swelling controlled drug release [27]. Transport from bupivacaine DMSO solutions is likely to be zero-order (time dependent 
and concentration independent), as high DMSO concentrations are known to lead to fluidisation of the SC lipids. The low lag time indicates that SNEDDS release from hydrogels is not hindered, possibly due to regions of low microviscosity of the 465 carbomer gels as only $50 \%$ of the polymer chains are ionised at pH $6.0[28,29]$. Surface moisture can also influence release from cross-linked polymeric matrixes. Considering that the SC of human eyelid skin has a high water content compared to other parts of the body [9], this high water content can hydrate and swell the polymer resulting in relaxation of the polymer chains and rapid SNEDD release.

470 LID-SNEDDS gels demonstrated high flux, which is 10-fold higher than recent reported values for other lipid-based nanoparticulate systems such as nanostructured lipid carriers [30] and 5-fold higher than EMLA cream (Table 2). LID-SNEDDS gels possessed a 10 fold higher flux compared to lidocaine NLCs (1\%) and 23-fold higher flux than free lidocaine (1\%) aqueous solutions previously reported [30]. These NLCs

475 were able to elicit near maximal anaesthesia in the tail flick test for 60 minutes and had a duration of action for at least 2 hours [30]. Although, further studies are needed to elucidate appropriate lidocaine concentration for adequate anaesthesia, the observed levels suggest that the gels (likely even with as low as $1 \%$ lidocaine loading) would be clinically relevant to elicit effective anaesthesia. Our nanoemulsions and 480 nano-enabled gels demonstrate linear flux with a short if any lag time ( 9 minutes) compared to EMLA ( 50 minutes) (Table 2). The shortened lag time suggest that LIDSNEDDS gels will have a rapid onset of action compared to clinically used preparations such as EMLA, which require 45 minutes to 1 hour to achieve an adequate anaesthetic effect [7]. The higher flux of the nano-enabled hydrogels compared to SNEDDS is linked to their supersaturated state ( $>1$ for hydrogels and 
0.013 for lidocaine as the maximum solubility of lidocaine within the SNEDDS isotropic mixture is $\sim 750 \mathrm{mg} \mathrm{g}^{-1}$ ).

Lidocaine flux across male eyelid skin was lower compared to skin from female subjects but results were not significant. The low number of male $(n=3)$ versus female $490(n=15)$ samples in our study might contribute to this. More samples are needed to draw definite conclusions, but male samples are difficult to obtain, as blepharoplasties are more common in women. Skin thickness might be a factor as studies have shown that male skin is $10-20 \%$ thicker than female skin ( $n=88,18-61$ years) [31]. However, other studies did not confirm this [32], and our male subjects are older than the reported

495 range in this study (age of male patients: $64,87,92$ ) and skin thickness is known to decrease with ageing [32].

A linear flux was observed for bupivacaine gels and with minimal lag time. (Figure 3, Table 4). Mouse skin used in this study possessed similar thickness to eyelid skin. Drug transport from these gels was best described by the Korsmeyer-Peppas model 500 and release was also non-Fickian (anomalous). Ex vivo tape stripping was used a surrogate for in vivo tape stripping experiments [33]. Complete removal of the SC was possible under our experimental conditions. However, the number of tapes needed to do so varied between formulations [19], with SNEDDS being the hardest to strip. BUPSNEDDS gels were able to provide localisation in the SC and dermis and resulted in $50538 \%$ lower levels in remaining homogenised skin.

Histopathology studies showed no apparent sign of skin irritation (e.g. oedema or erythema) on visual examination of skin eyelid samples with blank SNEDDS, LIDSNEDDS, and LID-SNEDDS gels with no sign of acanthosis or hyperkeratosis even after 9 hours of exposure. Analysis of mouse skin exposed to BUP SNEDDS gels for 51024 hours versus BUP DMSO showed no evident signs of irritation either. Transcutol 
$\mathrm{P}$, although used within approved FDA levels for skin products, can cause swelling of the lipid bilayer structures resulting in an intracutaneous drug depot effect, which improves drug retention within the skin and allows drugs to be released in a sustained manner.

\section{Funding}

These results highlight the potential clinical capability of nano-enabled anaesthetic hydrogels as a non-invasive anaesthetic procedure for eyelid surgery. Further in vivo studies are needed to elucidate the dose-efficacy and safety profile of our nanoenabled hydrogels.

\section{Acknowledgements}

This work was funded by the Royal Society (RG130542) and the National Institute for Health Research (NIHR) Biomedical Research Centre based at Moorfields Eye Hospital NHS Foundation Trust and UCL Institute of Ophthalmology and NIHR Eastern 525 CRN.

\section{Figure legends:}

Figure 1. TEM and AFM images of LID-SNEDDS (10\%) and LID-SNEDDS gels (10\%) and BUP-SNEDDS (2\%) BUP-SNEDDS gels (2\%): A, B: TEM images of LID-SNEDDS aqueous dispersions (1 in $1000 \mathrm{w} / \mathrm{v}$, Bar: 100nm); C: AFM images of LID-SNEDDS aqueous dispersions ( 1 in $1000 \mathrm{w} / \mathrm{v}$ ) with particles illustrating a spherical morphology with a height of $95.9 \pm 19.4 \mathrm{~nm}$ and a diameter of $93.8 \pm 16.8 \mathrm{~nm}$; D: AFM images of LID-SNEDDS gels aqueous dispersions (1 in $1000 \mathrm{w} / \mathrm{v}$ ) illustrating a spherical 
535 morphology with a height of $89.4 \pm 43.4 \mathrm{~nm}$ and a diameter of $90.2 \pm 40.6 \mathrm{~nm}$; E: TEM images of LID-SNEDDS gels aqueous dispersions (1 in $1000 \mathrm{w} / \mathrm{v}$, Bar: 100nm), F: TEM images of BUP-SNEDDS gels (2\%) aqueous dispersions (1 in $1000 \mathrm{w} / \mathrm{v}$ ), Bar: $100 \mathrm{~nm}$ ); G: AFM images of BUP-SNEDDS aqueous dispersions (1 in $1000 \mathrm{w} / \mathrm{v}$ ) illustrating a spherical morphology with a diameter of $45 \pm 7.4 \mathrm{~nm}$; H: AFM images of 540 BUP-SNEDDS gels aqueous dispersions (1 in $1000 \mathrm{w} / \mathrm{v}$ ) illustrating a spherical morphology with a diameter of $131.2 \pm 17.2 \mathrm{~nm}$.

Figure 2. Viscosity flow curves of LID-SNEDDS gels (10\%, black squares) and EMLA cream (red cycles) (A) and flux of lidocaine across artificial skin (B) and human eyelid 545 excised skin (C) [EMLA cream (black squares), LID-SNEDDS (10\%, green triangles), LID-SNEDDS gels (red cycles); LID-SNEDDS gels and LID-SNEDDS are statistical significant versus EMLA cream, $p<0.0001$, Repeated Measures One-way ANOVA GraphPad Prism 8.0].

550 Figure 3 . Solubility studies of bupivacaine in various media $\left(25^{\circ} \mathrm{C}, 24\right.$ hours) (A) and flux of bupivacaine across artificial skin (B) and mouse excised skin (C) [Bupivacaine in DMSO (2\%, black squares), BUP-SNEDDS (5\%, green triangles), BUP-SNEDDS gels ( $2 \%$, red cycles); No statistical significant differences between tested formulations apart from , $p=0.1092$, Repeated measures One-way ANOVA, Graph-Pad Prism 8.0].

555 Figure 4. Tape stripping studies of bupivacaine; Cumulative bupivacaine levels $(\mu \mathrm{g}$ $\mathrm{cm}^{-2}$ ) over tape number stripped after 30 minutes (A) and 60 minutes (B) exposure to formulations and cumulative mass of skin stripped per tape number after 30 minutes (A) and 60 minutes (B) exposure to formulations. [Bupivacaine in DMSO (2\%, black squares), BUP-SNEDDS (5\%, green triangles), BUP-SNEDDS gels ( $2 \%$, red cycles]. 
Figure 5. Micrographs of excised human eyelid and mouse skin (x10 magnification);

Human eyelid skin exposed for 9 hours to acetate buffer $(20 \mathrm{mM}, \mathrm{pH} 6.0 \pm 0.1)(\mathrm{A})$, blank SNEDDS (B), LID-SNEDDS (10\%) (C) and LID-SNEDDS gels (10\%) (D, E, where E1 indicates a hair follicle, E2 a tarsal gland and E3 an aprocrine gland). NMRI mouse skin exposed for 24 hours to acetate buffer $(20 \mathrm{mM}, \mathrm{pH} 6.0 \pm 0.1)(\mathrm{F})$, and

\section{References:}

1. Practice, P.S. BAAPS 2014 Data: Plastic Surgery Across the Pond Plummets. 2015 [cited 2018 27th April ]; Available from: http://www.plasticsurgerypractice.com/2015/01/baaps-data-plastic-surgery-fallsacross-pond/.

2. Trapasso, M. and A. Veneroso, Local anesthesia for surgical procedures of the upper eyelid using filling cannula: our technique. Plast Reconstr Surg Glob Open, 2014. 2(5): p. e143.

575 3. Vagefi, M.R., et al., Local anesthesia in oculoplastic surgery: precautions and pitfalls. Arch Facial Plast Surg, 2008. 10(4): p. 246-9.

4. de Araujo, D.R., et al., Strategies for delivering local anesthetics to the skin: focus on liposomes, solid lipid nanoparticles, hydrogels and patches. Expert Opin Drug Deliv, 2013. 10(11): p. 1551-63.

$580 \quad 5 . \quad$ Lalatsa, A., et al., Developing transcutaneous nanoenabled anaesthetics for eyelid surgery. Br J Ophthalmol, 2016. 100(6): p. 871-6.

6. Alster, T., Review of lidocaine/tetracaine cream as a topical anesthetic for dermatologic laser procedures. Pain Ther, 2013. 2(1): p. 11-9.

7. Sobanko, J.F., C.J. Miller, and T.S. Alster, Topical anesthetics for dermatologic

8. Bjerring, P. and L. Arendt-Nielsen, Depth and duration of skin analgesia to needle insertion after topical application of EMLA cream. Br J Anaesth, 1990. 64(2): p. 1737.

9. Pratchyapruit, W., et al., Functional analyses of the eyelid skin constituting the most soft and smooth area on the face: contribution of its remarkably large superficial corneocytes to effective water-holding capacity of the stratum corneum. Skin Res Technol, 2007. 13(2): p. 169-75.

10. Yellepeddi, V.K., Nanotechnology-based applications for the transdermal delivery of therapeutics., in Novel Delivery Systems for Transdermal and Intradermal Drug Delivery., R.F. Donelly and T.R.R. Singh, Editors. 215, John Wiley and sons: Chichester, West Sussex, UK. p. 125-146.

11. Zhang, J., et al., Molecular-level characterization of probucol nanocrystal in water by in situ solid-state NMR spectroscopy. Int J Pharm, 2012. 423(2): p. 571-6.

12. Alster, T., Erratum to: Review of Lidocaine/Tetracaine Cream as a Topical Anesthetic for Dermatologic Laser Procedures. Pain Ther, 2013. 2(1): p. 73.

13. Smith, L., et al., Orally Bioavailable and Effective Buparvaquone Lipid-Based Nanomedicines for Visceral Leishmaniasis. Mol Pharm, 2018. 15(7): p. 2570-2583. 
14. Lalatsa, A., et al., Delivery of peptides to the blood and brain after oral uptake of quaternary ammonium palmitoyl glycol chitosan nanoparticles. Mol Pharm, 2012. 9(6): p. 1764-74.

15. Lalatsa, A., et al., Chitosan amphiphile coating of peptide nanofibres reduces liver uptake and delivers the peptide to the brain on intravenous administration. J Control Release, 2015. 197: p. 87-96.

16. Serrano, D.R., et al., Tuning the Transdermal Delivery of Hydroquinone upon

17. Reddy, M.B., et al., Determining dermal absorption parameters in vivo from tape strip data. Pharm Res, 2002. 19(3): p. 292-8.

18. Kietzmann, M., D. Lubach, and H.J. Heeren, The mouse epidermis as a model in skin pharmacology: influence of age and sex on epidermal metabolic reactions and their circadian rhythms. Lab Anim, 1990. 24(4): p. 321-7.

19. Lademann, J., et al., The tape stripping procedure--evaluation of some critical parameters. Eur J Pharm Biopharm, 2009. 72(2): p. 317-23.

20. Leopold, C.S. and H.I. Maibach, Percutaneous penetration of local anesthetic bases: pharmacodynamic measurements. J Invest Dermatol, 1999. 113(3): p. 304-7.

620 21. Kouba, D.J., et al., Guidelines for the use of local anesthesia in office-based dermatologic surgery. J Am Acad Dermatol, 2016. 74(6): p. 1201-19.

22. Cho, C.-W., D.-B. Kim, and S.-C. Shin, Development of bioadhesive transdermal bupivacaine gels for enhanced local anesthetic action. Iranian Journal of Pharmaceutical Research, 2010. 11(2): p. 423-431.

23. Rommen, C., C.S. Leopold, and B.C. Lippold, Do local anesthetics have an influence on the percutaneous penetration of a model corticosteroid? An in vivo study using the vasoconstrictor assay. Eur J Pharm Sci, 1999. 9(2): p. 227-34.

24. Su, J., et al., Preparation and characterization of erythrocyte membrane cloaked PLGA/arsenic trioxide nanoparticles and evaluation of their in vitro anti-tumor effect.

25. Jimenez-Kairuz, A., D. Allemandi, and R.H. Manzo, Mechanism of lidocaine release from carbomer-lidocaine hydrogels. J Pharm Sci, 2002. 91(1): p. 267-72.

26. Gulsen, D. and A. Chauhan, Effect of water content on transparency, swelling, lidocaine diffusion in p-HEMA gels. Journal of Membrane Science, 2006. 269(1-2): p. 35-48.

27. Das, B., A.K. Nayak, and U. Nanda, Topical gels of lidocaine HCl using cashew gum and Carbopol 940: preparation and in vitro skin permeation. Int J Biol Macromol, 2013. 62: p. 514-7.

28. Majid Khan, G. and J.B. Zhu, Ibuprofen release kinetics from controlled-release tablets granulated with aqueous polymeric dispersion of ethylcellulose II: influence of several parameters and coexcipients. J Control Release, 1998. 56(1-3): p. 127-34.

29. Chakraborti, C.K., S. Sahoo, and P.K. Behera, Role of different biodegradable polymers on the permeability of ciprofloxacin. J Adv Pharm Technol Res, 2014. 5(3): p. 140-6.

30. Zhao, X., Y. Sun, and Z. Li, Topical anesthesia therapy using lidocaine-loaded nanostructured lipid carriers: tocopheryl polyethylene glycol 1000 succinate-modified transdermal delivery system. Drug Des Devel Ther, 2018. 12: p. 4231-4240.

31. Bailey, S.H., et al., The use of non-invasive instruments in characterizing human facial and abdominal skin. Lasers Surg Med, 2012. 44(2): p. 131-42.

32. Rahrovan, S., et al., Male versus female skin: What dermatologists and cosmeticians should know. Int J Womens Dermatol, 2018. 4(3): p. 122-130.

33. Trebilcock, K.L., J.R. Heylings, and M.F. Wilks, In vitro tape stripping as a model for in vivo skin stripping. Toxicol In Vitro, 1994. 8(4): p. 665-7. 
Table 1. Mean particle size, polydispersity and zeta potential of prepared batches of LA-SNEDDS and LA-SNEDDS gels $(n=4)$.

\begin{tabular}{|l|l|l|l|}
\hline Formulation & Particle size $(\mathrm{nm})$ & Polydispersity & Zeta Potential $(\mathrm{mV})$ \\
\hline LID-SNEDDS (10\%) & $200 \pm 3.6$ & $0.297 \pm 0.011$ & $-40.9 \pm 2.8$ \\
\hline LID-SNEDDS (20\%) & $216 \pm 21$ & $0.337 \pm 0.045$ & $-37.5 \pm 10.5$ \\
\hline LID-SNEDDS gel (10\%) & $249 \pm 26$ & $0.545 \pm 0.077$ & $-28.8 \pm 2.0$ \\
\hline BUP-SNEDDS (5\%) & $203 \pm 5$ & $0.282 \pm 0.028$ & $-42.6 \pm 2.5$ \\
\hline BUP-SNEDDS (2\%) & $206 \pm 5$ & $0.378 \pm 0.032$ & $-37.3 \pm 1.1$ \\
\hline BUP-SNEDDS gel (2\%) & $243 \pm 4$ & $0.32 \pm 0.077$ & $-38.7 \pm 7.7$ \\
\hline
\end{tabular}


Table 2. Skin permeation parameters for lidocaine across human eyelid skin from different nano-enabled formulations compared to commercial lidocaine formulations.

\begin{tabular}{|c|c|c|c|}
\hline Permeation Parameters & EMLA (2.5\%) & $\begin{array}{l}\text { LID-SNEDDS } \\
(10 \%)\end{array}$ & $\begin{array}{l}\text { LID-SNEDDS } \\
(10 \%)\end{array}$ \\
\hline Dose $(\mu \mathrm{g})$ & 25,000 & 80,000 & 80,000 \\
\hline $\operatorname{JSS}_{40-240}\left(\mu \mathrm{g} \mathrm{cm}^{-2} \mathrm{~h}^{-1}\right)$ & $30.0 \pm 4.2$ & $93.6 \pm 30.0$ & $\begin{array}{l}155.4 \pm 37.2(F: 146.4 \\
M: 117.0)^{* *}\end{array}$ \\
\hline Lag time $(\mathrm{h})$ & $0.83 \pm 0.21$ & $0.29 \pm 0.48$ & $\begin{array}{l}0.15 \pm 0.32 \\
(F: N D, \\
M: 10.6 \pm 33.1)\end{array}$ \\
\hline$Q_{90}\left(\mu \mathrm{g} \mathrm{cm}^{-2}\right)$ & $23.2 \pm 13.5$ & $116.9 \pm 28.4$ & $223.1 \pm 45.6$ \\
\hline$Q_{240}\left(\mu \mathrm{g} \mathrm{cm}^{-2}\right)$ & $124.9 \pm 19.9$ & $369.6 \pm 63.6$ & $621.8 \pm 72.4$ \\
\hline $\mathrm{Kp}(\mathrm{cm} / \mathrm{h})$ & $1.2010^{-3}$ & $1.1710^{-3}$ & $1.9410^{-3}$ \\
\hline$\left(\mathrm{cm}^{2} / \mathrm{h}\right)$ & $0.810^{-4}$ & $1.0810^{-4}$ & $1.7710^{-4}$ \\
\hline $\mathrm{EF}$ & NA & 3.12 & 5.18 \\
\hline Thick & $0.068 \pm 0.020$ & $0.092 \pm 0.005$ & $0.091 \pm 0.006$ \\
\hline Patie & $>65 y$ & $62-92$ & $56-74$ \\
\hline Gender distribution & $3 F: 1 M$ & $3 F: 3 M$ & $15 \mathrm{~F}: 3 \mathrm{M}$ \\
\hline \multicolumn{4}{|c|}{$\begin{array}{l}\text { Key: Dapp: Apparent diffusion co-efficient, EF: Enhancement factor, F: female, Jss } \mathbf{S}_{40-240} \text { : } \\
\text { Flux at steady state (40-240 minutes), Kp: Permeability co-efficient, M: male, NA: Not } \\
\text { applicable, ND: Not detectable under experimental conditions, } \mathbf{Q}_{90}, \mathbf{Q}_{240}: \text { Cumulative } \\
\text { amount permeated after } 90 \text { or } 240 \text { minutes, }{ }^{*}: \text { Age was not reported for all samples, }{ }^{* *}: \text { no } \\
\text { statistical differences between genders. }\end{array}$} \\
\hline
\end{tabular}


Table 3. Curve fitting of the ex vivo human eyelid and mouse skin permeation data of commercial and nano-enabled formulations.

\begin{tabular}{|l|l|l|l|l|l|}
\hline Formulation & $\begin{array}{l}\text { Zero } \\
\text { Order }\left(\mathrm{R}^{2}\right)\end{array}$ & $\begin{array}{l}\text { First Order } \\
\left(\mathrm{R}^{2}\right)\end{array}$ & $\begin{array}{l}\text { Higuchi } \\
\left(\mathrm{R}^{2}\right)\end{array}$ & $\begin{array}{l}\text { Hixson } \\
\text { Crowell }\left(\mathrm{R}^{2}\right)\end{array}$ & $\begin{array}{l}\text { Korsmeyer- } \\
\text { Peppas }\left(\mathrm{R}^{2}\right)\end{array}$ \\
\hline EMLA & 0.910 & 0.821 & 0.916 & 0.900 & $\begin{array}{l}\mathbf{0 . 9 2 3} \\
(\mathrm{n}=1.29)\end{array}$ \\
\hline LID-SNEDDS (10\%) & 0.981 & 0.901 & 0.972 & 0.984 & $\begin{array}{l}\mathbf{0 . 9 9 3} \\
(\mathrm{n}=1.08)\end{array}$ \\
\hline LID-SNEDDS gel & 0.986 & 0.921 & 0.989 & 0.986 & $\begin{array}{l}\mathbf{0 . 9 9 8} \\
(\mathrm{n}=0.976)\end{array}$ \\
\hline BUP in DMSO (2\%) & 0.989 & 0.845 & 0.965 & 0.974 & $\begin{array}{l}0.989 \\
(\mathrm{n}=1.08)\end{array}$ \\
\hline BUP-SNEDDS (5\%) & 0.988 & 0.766 & 0.967 & 0.988 & $\begin{array}{l}\mathbf{0 . 9 9 7} \\
(\mathrm{n}=0.817)\end{array}$ \\
\hline BUP-SNEDDS gel (2\%) & 0.983 & 0.637 & 0.966 & 0.979 & $\begin{array}{l}\mathbf{0 . 9 8 4} \\
(\mathrm{n}=0.933)\end{array}$ \\
\hline
\end{tabular}


Table 4. Skin permeation parameters for bupivacaine across mouse skin from different nano-enabled formulations.

\begin{tabular}{|c|c|c|c|}
\hline Permeation Parameters & $\begin{array}{c}\text { BUP in DMSO } \\
(2 \%)\end{array}$ & $\begin{array}{c}\text { BUP-SNEDDS } \\
(5 \%)\end{array}$ & $\begin{array}{c}\text { BUP-SNEDDS gel } \\
(2 \%)\end{array}$ \\
\hline Dose $(\mu \mathrm{g})$ & 20,000 & 20,000 & 20,000 \\
\hline JSS ${ }_{0-300}\left(\mu \mathrm{g} \mathrm{cm}^{-2} \mathrm{~h}^{-1}\right)$ & $51.86 \pm 15.27$ & $98.20 \pm 40.05$ & $72.35 \pm 14.44$ \\
\hline Lag time $(\mathrm{h})$ & $0.154 \pm 0.141$ & $0.028 \pm 0.029$ & $0.002 \pm 0.003$ \\
\hline$Q_{30}\left(\mu \mathrm{g} \mathrm{cm}^{-2}\right)$ & $30.64 \pm 7.17$ & $78.62 \pm 39.93$ & $35.89 \pm 11.98$ \\
\hline$Q_{60}\left(\mu \mathrm{g} \mathrm{cm}^{-2}\right)$ & $57.52 \pm 17.57$ & $229.91 \pm 205.82$ & $84.63 \pm 19.01$ \\
\hline$Q_{300}\left(\mu \mathrm{g} \mathrm{cm}^{-2}\right)$ & $255.97 \pm 43.86$ & $526.37 \pm 267.46$ & $338.06 \pm 68.57$ \\
\hline$Q_{1440}(\mu \mathrm{g} \mathrm{cm-2})$ & $664.3 \pm 368.1$ & $3071.5 \pm 2639.4$ & $984.5 \pm 240.0$ \\
\hline $\mathrm{Kp}(\mathrm{cm} / \mathrm{h})$ & $2.5910^{-3}$ & $4.9110^{-3}$ & $3.2710^{-3}$ \\
\hline D app $\left(\mathrm{cm}^{2} / \mathrm{h}\right)$ & $2.3610^{-4}$ & $4.1510^{-4}$ & $2.0110^{-4}$ \\
\hline EF & NA & 1.89 & 1.40 \\
\hline Thickness (cm) & $0.091 \pm 0.004$ & $0.091 \pm 0.014$ & $0.083 \pm 0.015$ \\
\hline Skin levels after $24 \mathrm{~h}$ & $664.3 \pm 368.1$ & $3356.7 \pm 2577.4$ & $2988.2 \pm 758.1$ \\
\hline \multicolumn{4}{|c|}{$\begin{array}{l}\text { Key: Dapp: Apparent diffusion co-efficient, EF: Enhancement factor, } \mathbf{F}: \text { female, Jss } \mathbf{J}_{0-300} \text { : } \\
\text { Flux at steady state ( } 30-300 \text { minutes), Kp: Permeability co-efficient, } \mathbf{M} \text { : male, NA: Not } \\
\text { applicable, } \mathbf{Q}_{\mathbf{3 0}}, \mathbf{Q}_{60}, \mathbf{Q}_{300}, \mathbf{Q}_{1440} \text { : Cumulative amount permeated after } 30,60,300 \text { or } 1440 \\
\text { minutes. }\end{array}$} \\
\hline
\end{tabular}


Table 5. Calculated skin permeation parameters for bupivacaine across mouse skin from different nano-enabled formulations from tape stripping experiments.

\begin{tabular}{|c|c|c|c|c|c|c|}
\hline \multirow{2}{*}{ Time } & \multirow{2}{*}{ Formulation } & \multirow{2}{*}{ Lsc $(\mu \mathrm{m})$} & \multirow{2}{*}{$\mathrm{K}_{\mathrm{sc} / \mathrm{v}}$} & \multicolumn{3}{|c|}{ Bupivacaine levels $(\mu \mathrm{g})$} \\
\hline & & & & $\begin{array}{c}\text { SC }(15 \mu \mathrm{m}) \\
\text { TS number } \\
\text { (Mean } \pm \text { SD) }\end{array}$ & Dermis & $\begin{array}{l}\text { Homogenised } \\
\text { skin }\end{array}$ \\
\hline \multirow[t]{3}{*}{$0.5 \mathrm{~h}$} & BUP DMSO & $35.0 \pm 2.3$ & $194.4 \pm 60.9$ & $\begin{array}{l}2.81 \pm 1.43 \\
(14 \pm 3)\end{array}$ & $4.83 \pm 0.67$ & $395.6 \pm 45.1$ \\
\hline & BUP-SNEDDS & $26.3 \pm 5.9$ & $1578.6 \pm 101.5$ & $\begin{array}{l}29.67 \pm 5.23 \\
(23 \pm 5)\end{array}$ & $25.36 \pm 11.6$ & $219.4 \pm 63.4$ \\
\hline & $\begin{array}{l}\text { BUP-SNEDDS } \\
\text { gels }\end{array}$ & $28.6 \pm 3.6$ & $1219.0 \pm 170.1$ & $\begin{array}{l}25.37 \pm 0.99 \\
(20 \pm 2)\end{array}$ & $24.54 \pm 1.63$ & $285.7 \pm 115.7$ \\
\hline \multirow[t]{3}{*}{$1 \mathrm{~h}$} & BUP DMSO & $41.1 \pm 10.5$ & $1292.3 \pm 705.6$ & $\begin{array}{l}23.80 \pm 9.29 \\
(15 \pm 5)\end{array}$ & $29.92 \pm 14.62$ & $9848.0 \pm 627.7$ \\
\hline & BUP-SNEDDS & $34.9 \pm 5.0$ & $1311.5 \pm 309.3$ & $\begin{array}{l}27.74 \pm 7.24 \\
(17 \pm 5)\end{array}$ & $32.80 \pm 6.83$ & $\begin{array}{l}10777.8 \\
1912.1\end{array}$ \\
\hline & $\begin{array}{l}\text { BUP-SNEDDS } \\
\text { gels }\end{array}$ & $29.8 \pm 6.7$ & $1403.2 \pm 340.4$ & $\begin{array}{l}29.64 \pm 9.33 \\
(18 \pm 2)\end{array}$ & $31.81 \pm 3.60$ & $6106.2 \pm 327.3$ \\
\hline
\end{tabular}



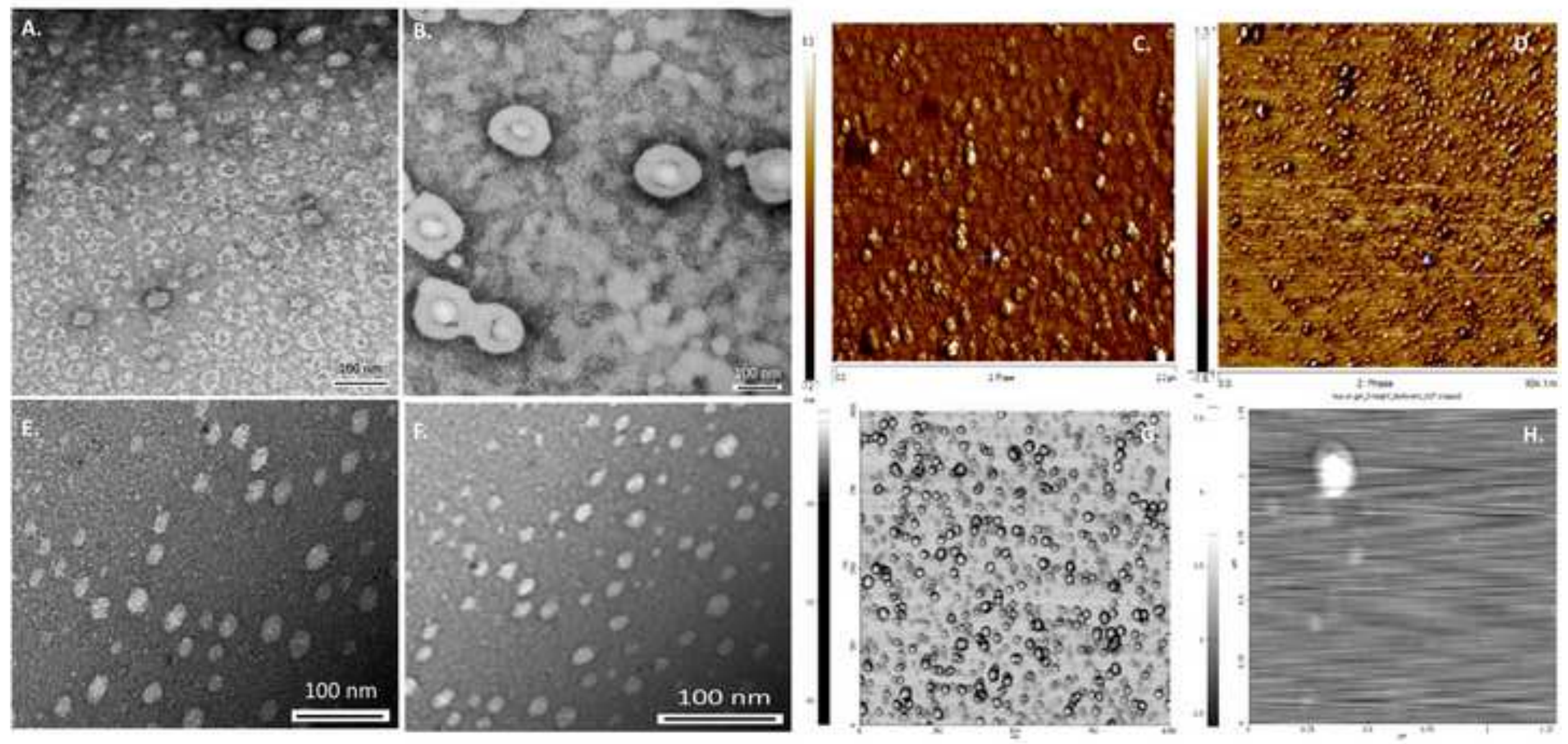


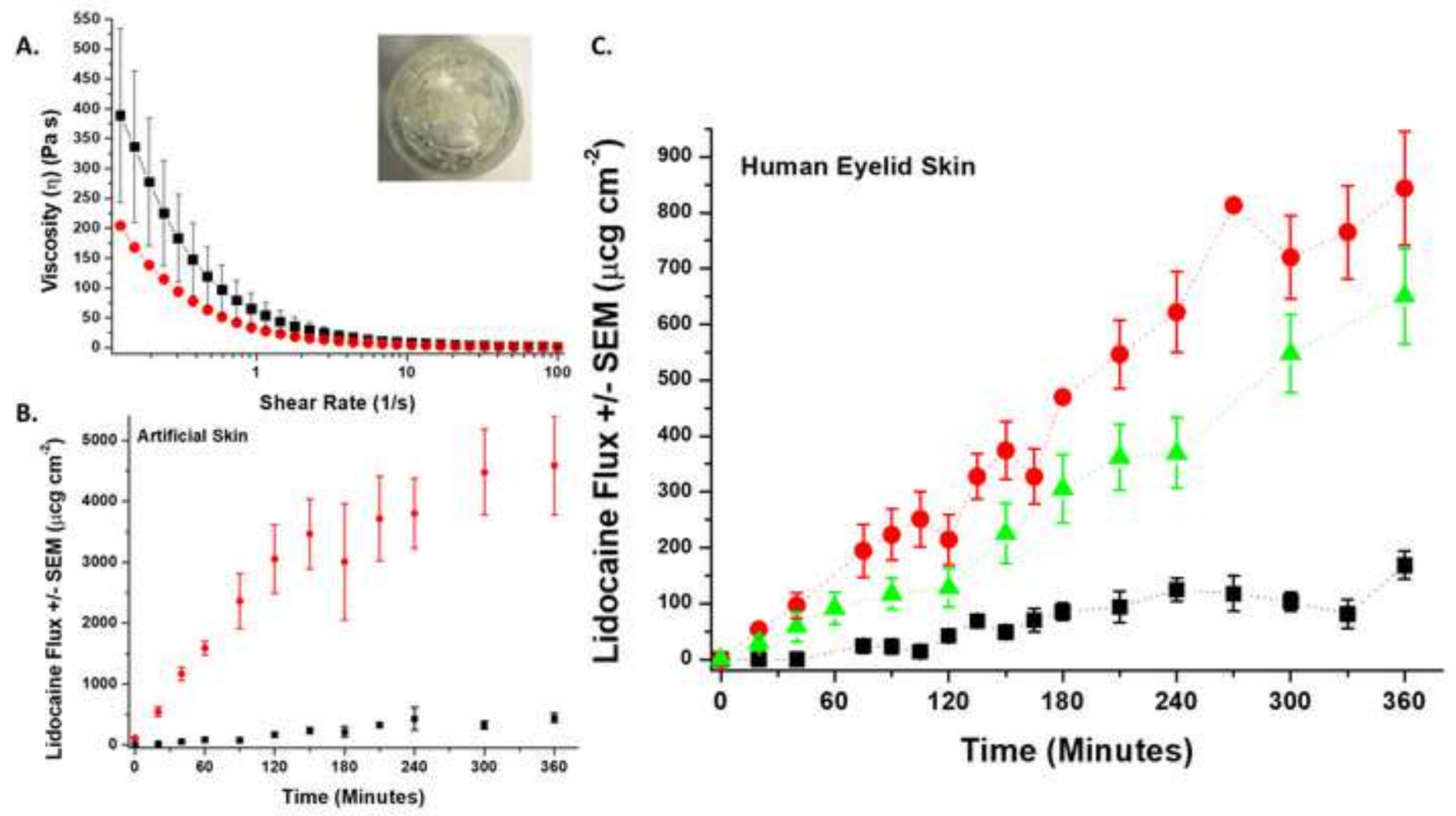

B.

Time (Minutes)

c.

근 300 

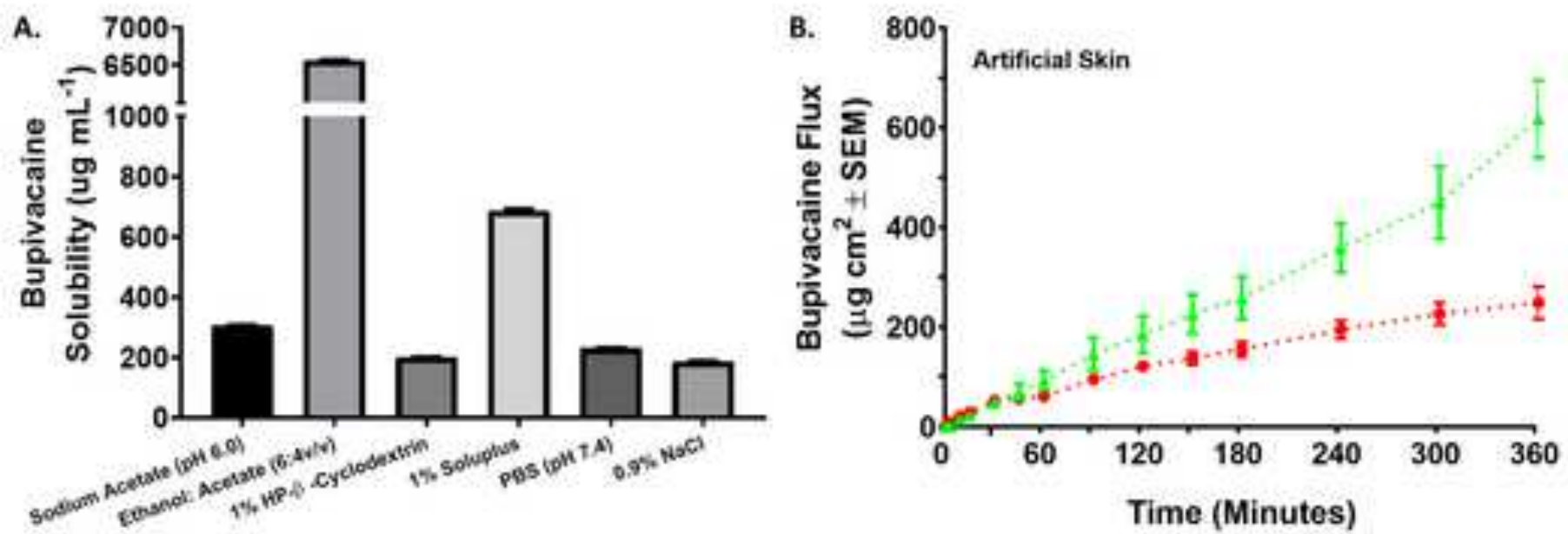

c.

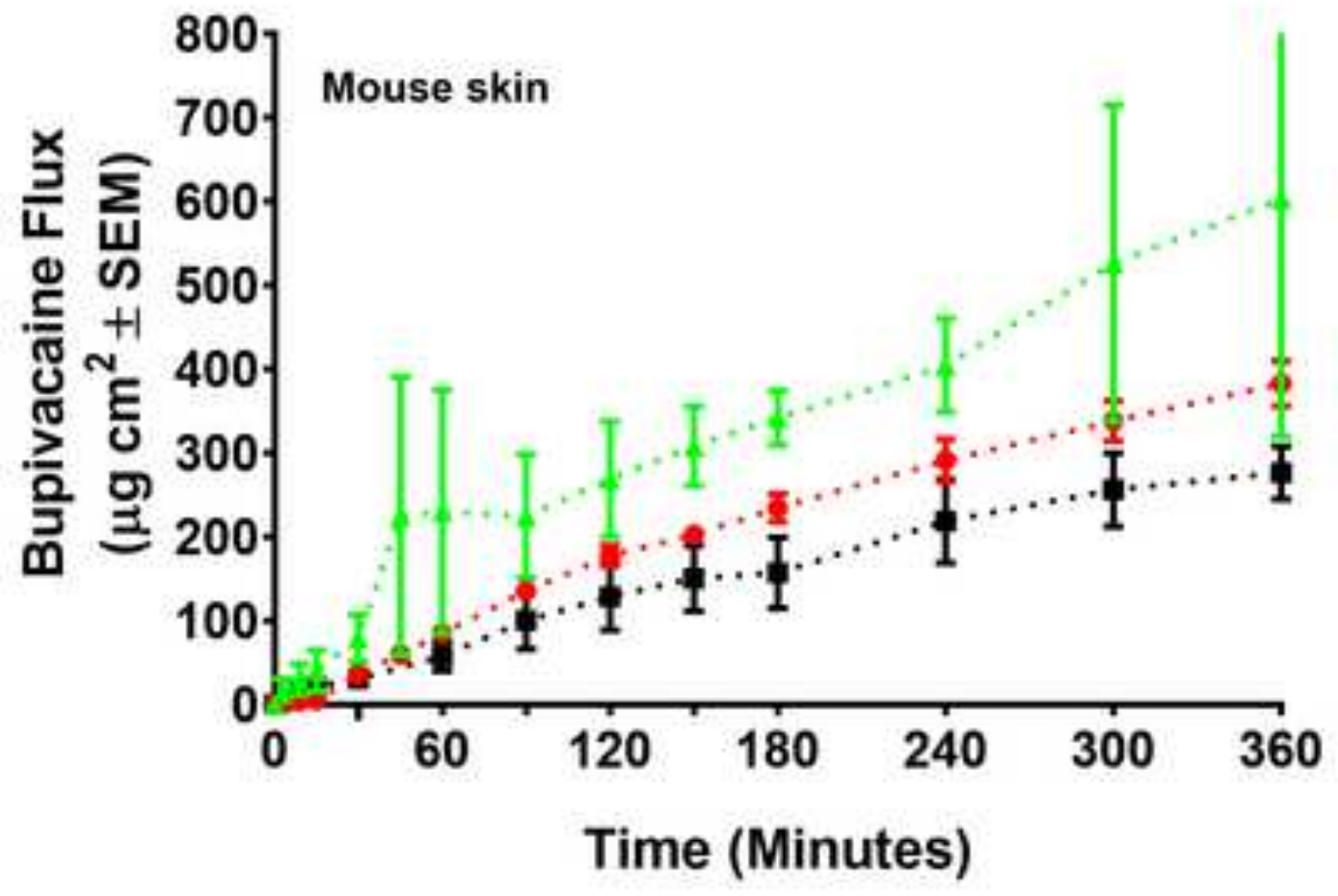



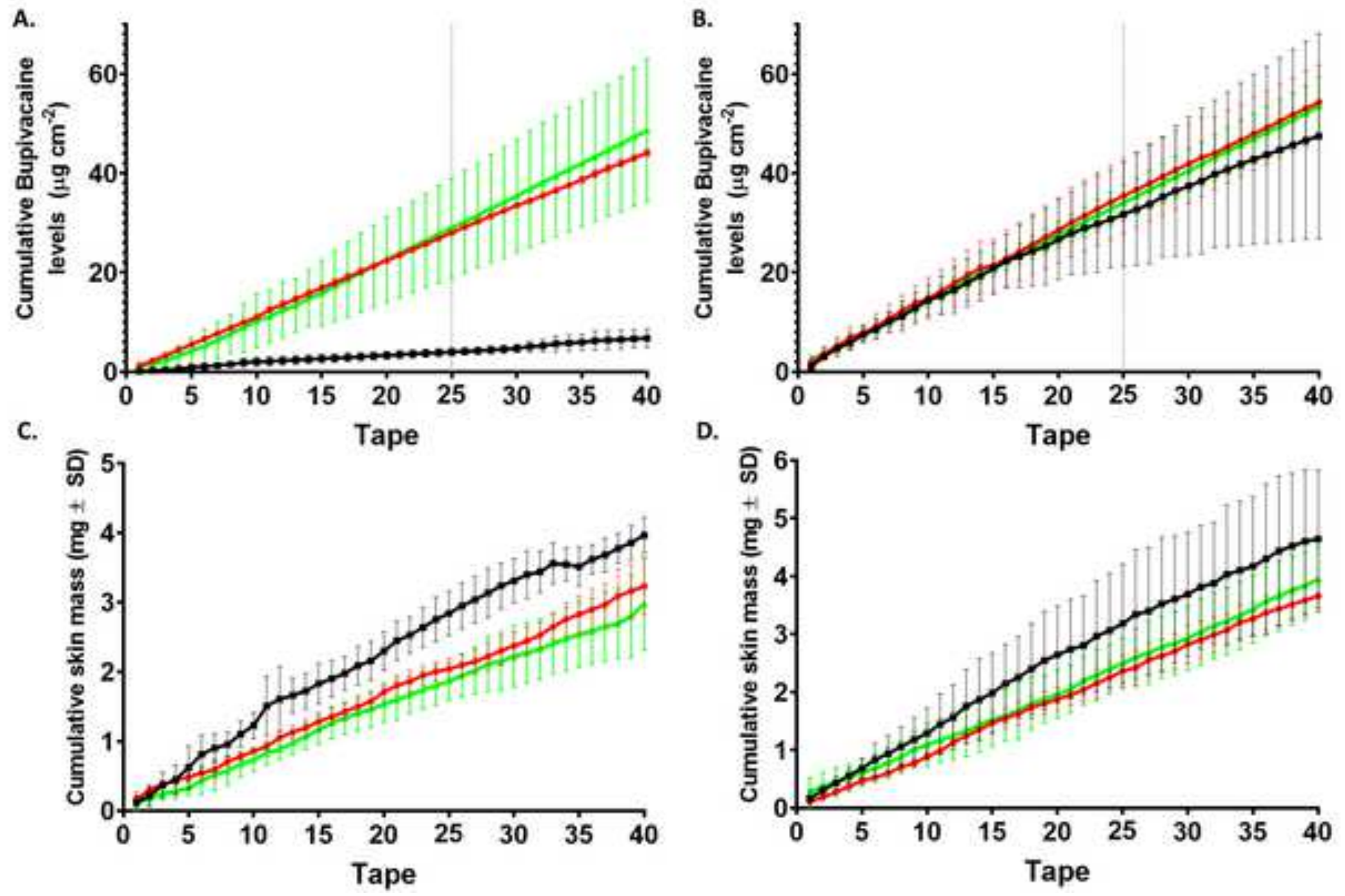

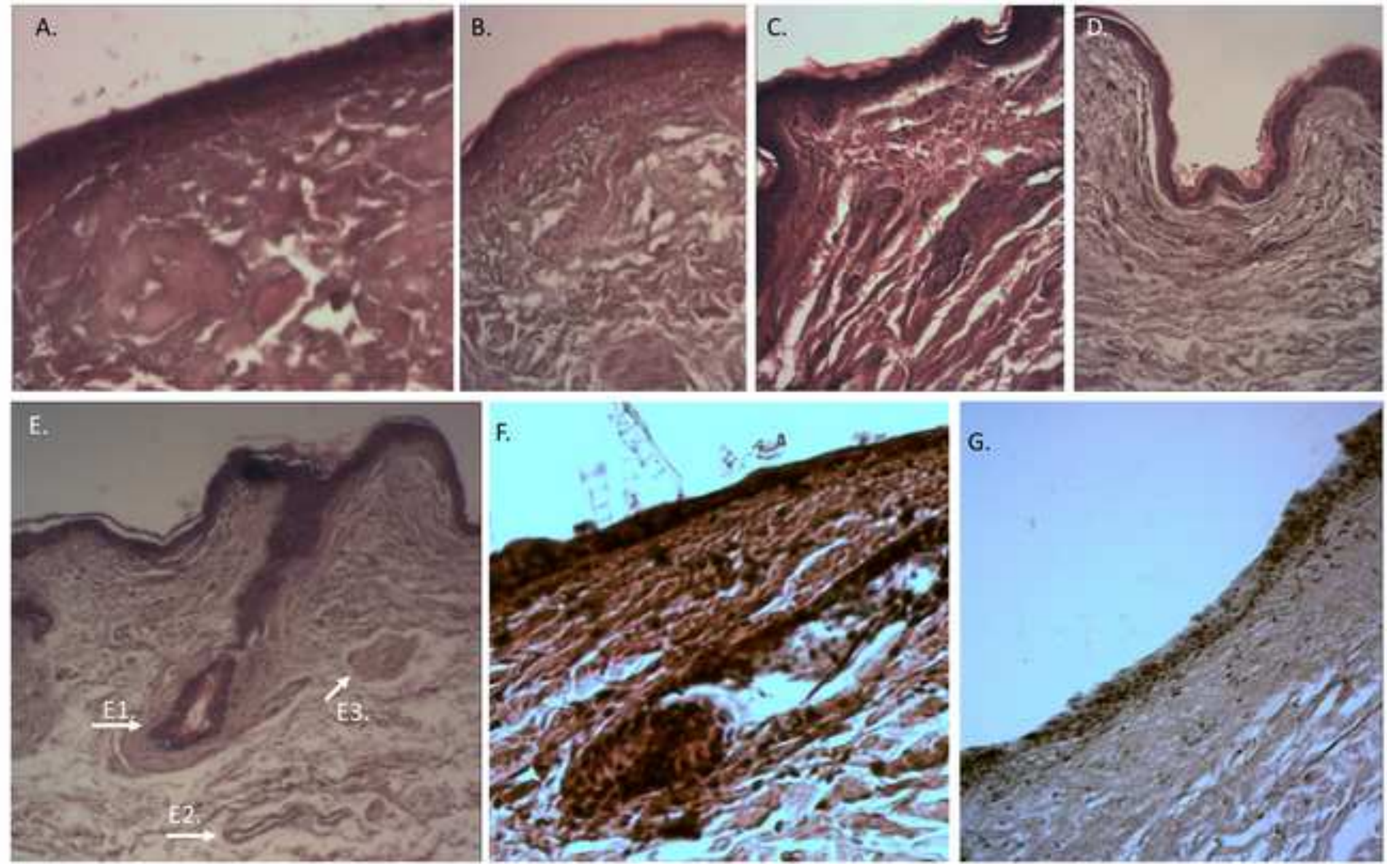

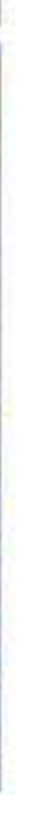
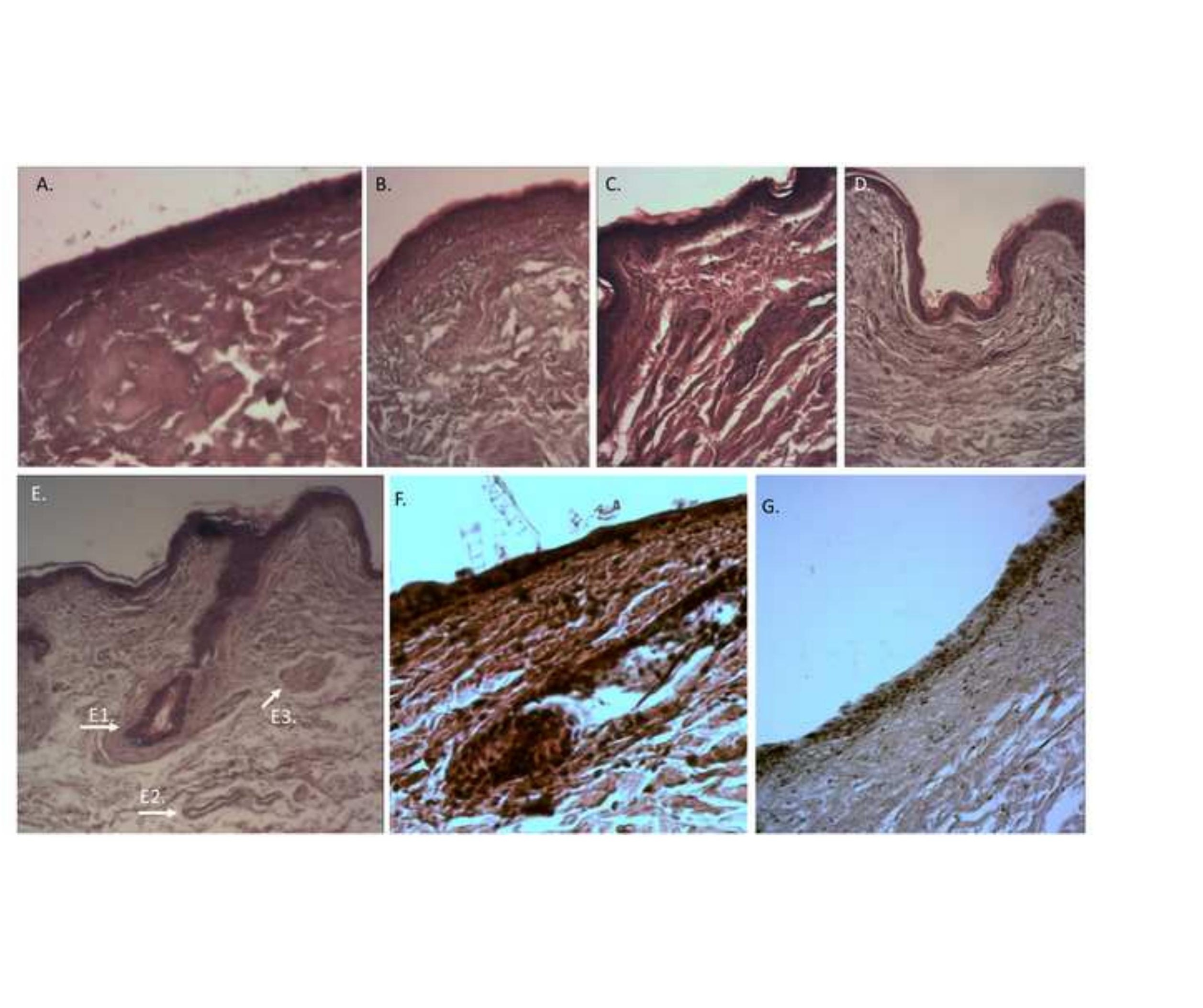